\title{
Fund-holders and child mental health services
}

\author{
T. I. R. Mutale
}

\begin{abstract}
Three hundred randomly selected fund-holding general practitioners were sent a questionnaire that asked them to Indicate thelr priortiles for child mental heotth services. They were also asked to rate their local child mental health services; 210 (70\%) returned completed questionnaires. Items accorded the highest priority by the lorgest number of GPs included written communication, short walting time following referral, senstitutity to pottient's cultural bockground, child sexual abuse services, and mental handicap services. Child poychiatrists were seen as the most essential members of multidisciplinary feams, and family therapy was the most popular choice of treatment. Financial considerations did not appear to dictate CPs' cholces. About half of respondents rated their local services as barely satistactory, unsatistactory or extremely unsatisfactory.
\end{abstract}

A general practitioner sees a child three to seven times a year and is well placed to assess the needs of children with psychological disorders. Priorities set by GPs are important because they reflect local needs. It is not therefore surprising that providers have been urged to establish priorities that are sensitive to the views of GPs.

Recent NHS reforms have increased the influence of GPs on the development of both primary and secondary care services. In addition, the appointment of fund-holding practices who are direct purchasers has made it possible for GPs to influence the pattern of specialist services. Their influence is bound to increase with the withdrawal of opposition to fund-holding by the General Medical Services Committee (GMSC) and because as from April 1994, $40 \%$ of GPs became fund-holders. This is the first study in the UK to determine fund-holders' priorities for child mental health services.

\section{The study}

During May and June 1993, 300 fund-holding practices were chosen using a random numbers table from a list of first and second wave practices in the UK (Institute of Health Services Management, 1993). One GP was chosen from each of the 30 practices using a random numbers table (Daniel, 1991) and was sent a questionnaire together with a personally addressed covering letter. Three weeks later another questionnaire was sent to GPs who had not responded.

The questionnaire had a list of services, treatments and professionals relevant to child mental health. GPs were asked to rank each item as priority or essential; important, but not essential; not important. If they did not have sufficient knowledge they were asked to tick the column headed 'no comment'. One section was left blank for respondents to add items not on the list.

To determine whether or not financial factors influenced GPs' attitude to treatments or professionals, respondents were asked to rank the following items: all professionals involved with a particular child should be charged for separately (rather than one fee to cover all professionals); all treatments given to a child should be charged separately (rather than one fee for all treatments); and that no extra treatments, unless previously agreed, should be given without prior consultation.

GPs were also asked to rate their local child mental health services as: excellent; very good; good; barely satisfactory; unsatisfactory; extremely unsatisfactory.

A final section invited GPs to make additional comments on their child mental health services.

\section{Findings}

Out of $300(70 \%)$ GPs, 210 returned completed questionnaires. The commonest reason given for non completion of questionnaires was lack of time.

Table 1 shows the types of services fundholders regarded as priorities in child mental health services. Service items seen as priorities 
Table 1. Fund-holders' priorities for child mental health units: services and speciallities. Numbers (\%) refer to general practitioners

\begin{tabular}{llcc}
\hline & \multicolumn{3}{c}{ CPs' views (n=210) } \\
\cline { 2 - 4 } Services or speciality & Priority/essential & Important but not essential & Not important \\
\hline Written reports & $160(88.0)$ & $36(17.1)$ & $6(2.9)$ \\
Short walting time after referral & $158(75.2)$ & $51(24.3)$ & $10.5)$ \\
Child sexual abuse senvice & $158(75.2)$ & $52(24.8)$ & $0(0.0)$ \\
Sensittlity to client's culture & $127(60.4)$ & $71(33.8)$ & $10(4.8)$ \\
Mental handicap & $125(59.5)$ & $79(37.6)$ & $6(2.9)$ \\
Emergency in-patient beds & $111(52.9)$ & $74(35.2)$ & $25(11.9)$ \\
Alcohol and drug addiction & $100(47.6)$ & $102(48.5)$ & $6(2.9)$ \\
Youth counselling & $92(43.8)$ & $108(51.4)$ & $10(4.8)$ \\
Appointments made over telephone & $89(42.4)$ & $102(48.5)$ & $19(9.1)$ \\
In-patient beds (13 to 17 years) & $86(41.0)$ & $103(49.0)$ & $21(10.0)$ \\
Overdose assessment & $78(37.1)$ & $113(53.8)$ & $17(8.1)$ \\
In-patient beds (0 to 12 years) & $62(29.5)$ & $111(52.9)$ & $37(17.6)$ \\
Day hospital (13 to 17 years) & $61(29.0)$ & $118(56.2)$ & $31(14.8)$ \\
Day hospital (0 to 12 years) & $60(28.5)$ & $110(52.4)$ & $37(17.6)$ \\
Out of hours/weekend service & $27(12.8)$ & $119(56.7)$ & $64(30.5)$ \\
Practice based regular meetings & $15(7.1)$ & $119(56.7)$ & $76(36.2)$ \\
Joint assessment of patients & $9(4.3)$ & $93(44.3)$ & $108(51.4)$ \\
\hline
\end{tabular}

by the greatest number of GPs were written reports and a short waiting time after referral. The specialist service seen as a priority by the greatest number was the assessment and treatment of sexually abused children. Joint assessment of children and regular practice visits by child psychiatrists came at the bottom of the priority list.

Table 2 shows fund-holders' priorities for child mental health professionals. Child psychiatrists were at the top of the priority list and music therapists at the bottom.

Table 3 shows the types of treatment fundholders thought should have priority. Family therapy was seen as a priority by the greatest number of GPs.
Tables 2 and 3 also show how GPs rated financial factors.

Of the $210 \mathrm{GPs}$, three $(1.4 \%)$ rated their local child mental health service as excellent, 16 (7.6) as very good, 79 (37.6) as good, 67 (31.9) as barely satisfactory, 33 (15.7) as unsatisfactory, and $12(5.7)$ as extremely unsatisfactory.

Out of 210 GPs, $40(19 \%)$ indicated further concerns in additional comments on local services. Thirty (14\%) commented on poor resources and long waiting times after referral. Twenty (10\%) indicated their dissatisfaction with communication: no written reports on children seen; vague summaries; too much theory; and the lack of

Table 2. Fund-holders' priorities: child mental health services staff. Numbers (\%) refer to general practitioners

\begin{tabular}{lllc}
\hline & \multicolumn{3}{c}{ GPs' viows $(\boldsymbol{n}=210)$} \\
\cline { 2 - 4 } Protessional & Priortly/escential & Important but not escential & Not important \\
\hline Psychiatrist & $188(89.5)$ & $19(9.0)$ & $3(1.5)$ \\
Psychologist & $166(79.0)$ & $39(18.6)$ & $5(2.4)$ \\
CPN & $157(75.1)$ & $46(21.9)$ & 7 \\
Soclal worker & $141(67.1)$ & $59(28.1)$ & $10(4.8)$ \\
Psychotherapist & $126(60.0)$ & $69(32.9)$ & $12(5.7)$ \\
Art therapist & $6(2.9)$ & $74(35.2)$ & $124(59.0)$ \\
Drama therapist & $5(2.4)$ & $68(32.4)$ & $131(62.3)$ \\
Music therapist & $4(1.9)$ & $71(33.8)$ & $129(61.4)$ \\
Separate charges for professionals who & $38(18.1)$ & $80(38.1)$ & $92(43.8)$ \\
see a child & & & \\
\hline
\end{tabular}


Table 3. Fund-holders' priorities for child mental health services: treatment methods. Numbers (\%) refer to general practitioners

\begin{tabular}{lccc}
\hline & \multicolumn{3}{c}{ GP' views (n=210) } \\
\cline { 2 - 4 } Treatment & Priority/essential & Important but not essential & Not important \\
\hline Family therapy & $139(66.2)$ & $66(31.4)$ & $4(1.9)$ \\
Counselling & $106(50.5)$ & $98(46.7)$ & $5(2.3)$ \\
Behaviour therapy & $59(28.1)$ & $120(57.1)$ & $29(13.8)$ \\
Marital therapy & $51(24.3)$ & $114(54.3)$ & $41(19.4)$ \\
Play therapy & $34(16.2)$ & $119(56.7)$ & $54(25.7)$ \\
Group therapy & $26(12.3)$ & $141(67.1)$ & $39(18.6)$ \\
Analytic therapy & $19(9.1)$ & $99(47.1)$ & $92(43.8)$ \\
Art therapy & $15(7.1)$ & $100(47.6)$ & $93(44.3)$ \\
Drama therapy & $5(2.4)$ & $91(43.3)$ & $113(53.8)$ \\
Music therapy & $3(1.4)$ & $97(46.2)$ & $110(52.4)$ \\
Acupuncture & $1(0.5)$ & $23(11.0)$ & $185(88.0)$ \\
Homeopathy & $0(0.0)$ & $26(12.4)$ & $183(87.1)$ \\
Cost treatments separately & $50(23.8)$ & $84(40.0)$ & $73(34.8)$ \\
No extra treatments without telling GP first & $46(21.9)$ & $69(32.9)$ & $92(43.8)$ \\
\hline
\end{tabular}

practical suggestions. One GP indicated that his practice was so dissatisfied with the local service that negotiations had began to establish a contract with a unit in another area.

\section{Comment}

This study shows that child mental health units should pay attention to written communication and waiting time after referral at their audit meetings.

Nearly two-thirds of fund-holders regarded sensitivity to the client's cultural background as a priority. This is bound to be an important factor in the quality of service provided to ethnic minorities and is consistent with a recent suggestion that training in ethnic issues should be available to child psychiatry senior registrars (Nicol, 1992).

A striking finding was that child sexual abuse work was chosen as a priority service by a high number of GPs. The choice is supported by studies that have shown that child sexual abuse is much more widespread than previously thought (Baker \& Duncan, 1985; Anderson et al, 1993) and associated with childhood psychological problems (Mannarino \& Cohen, 1986) as well as psychiatric disorder in adulthood (Beitchman et al, 1992). Intrafamilial sexual abuse probably places a GP whose list includes abusing and abused family members in a difficult position.

The high priority given to sexual abuse services suggests that GPs want to be able to pass on complex cases to their local service.
Another possible factor is that the Children Act (1989) emphasises working with parents (partnership) and fewer cases reach the courts. GPs may therefore be put under pressure to arrange assessment and treatment for cases that would have otherwise been dealt with by the courts. Clearly the lack of local expertise is keenly felt. The increased awareness of sexual abuse in the population, and the rise in the number of reported cases indicate that sexual abuse is set to become a significant part of the GPs' work-load.

The emphasis on mental handicap services is probably a reflection of the resettlement into the community of people with learning disabilities and the resultant demands made on the general practitioner to manage challenging behaviours.

Given the interest in children admitted to adult psychiatric wards (Dyer, 1992; Malek \& Children's Society, 1991), it was surprising that only $30 \%$ to $40 \%$ of fund-holders thought inpatient or day services a priority. Perhaps inpatient care is perceived to have disadvantages such as disruption of the child's usual environment; and the value of child psychiatric inpatient treatment is uncertain, even among child psychiatrists (Allesi, 1993; Pfeiffer et al 1990). Possibly also the number of children who require in-patient or day hospital care is so small that an individual general practitioner probably sees so few that there might seem no great need for such services.

Child psychiatrists are seen as the most essential member of the child mental health team. This suggests that the psychiatrist is 
viewed as the most powerful member of the multidisciplinary team even though team members may regard all team members as equal. Alternatively, GPs may identify with the medical member of the team, and are not sure what role non-medical members of the team have. Furthermore, those GPs who apply the 'medical model' to childhood psychological disorders probably regarded non-medical members of the team as less essential.

Sixty per cent of GPs regarded art, drama or music therapists as of no importance. By contrast, the child psychotherapist was seen as a priority by $60 \%$ of GPs. This suggests that child mental health units will find it easier to get fund-holders' support for the recruitment of child psychotherapists than for art, drama and music therapists.

That family therapy was given such a high priority suggests that GPs regard psychological problems in children as having a family basis and were perhaps also influenced by the knowledge that most child psychiatrists favour family interventions.

That shorter term structured behavioural methods were ranked third even though they are cheaper suggests that economic factors did not dictate choice of treatment. Moreover, only a fifth of GPs thought it essential that professionals or treatments associated with a particular child be charged for separately or that extra treatments should not be given without prior consultation.

These findings are important for several reasons. The consultation fees for a professional who sees fewer children than others, for example a psychotherapist, may be considered too high if costed separately. Setting a standard unit fee makes it possible for child mental health units to charge lower fees because professionals who see more children, or receive a lower salary, help subsidise those who do not. Different treatments are unlikely to cost the same, and more expensive treatments disproportionately raise the cost of a package that consists of several different types of therapy. A child seen by one mental health unit may require additional treatments from another specialist unit which may be delayed if a fund-holding practice insisted on being consulted before additional treatments are given.

Only a fifth of fund-holders thought joint patient assessment or regular meetings with a child psychiatrist were priorities and a half thought joint patient assessment of no importance (cf. Brown \& Tower, 1990). This suggests that child psychiatrists may find it difficult to establish face to face links with fund-holding practices.

It is worrying that about half of GPs rated their local services as barely satisfactory, unsatisfactory or extremely unsatisfactory and all the more striking because the practitioners came from all over the UK.

Child mental health units must plan services that are sensitive to the needs of their clients and the views of GPs. The balance of power has now shifted from providers to purchasers and secondary care units cannot ignore the opinions of GPs, the major purchasers of services.

\section{References}

Aulesi N. (1993) Resolved: two-week psychiatric hospitalisations of children and adolescents are useless. Negative. Journal of the American Academy of Child and Adolescent Psychiatry. 32, 217-220.

ANDERson, J., Martin, J., MuLLen, P., Romans, S. \& HERBison. P. (1993) Prevalence of childhood sexual abuse experiences in a community sample of women. Joumal of the American Academy of Child and Adolescent Psychiatry, 32, 911-919.

BAKER, A. W. \& Duncan, S. P. (1985) Child sex abuse: A study of prevalence in Great Britain. Child Abuse \& Neglect, 9, 457-467.

BerTChMAN, J. H., ZUCKER, K. J., HOOD, J. E., DACOSTA, G. A. et al (1992) A review of the long-term effects of child sexual abuse. Child Abuse \& Neglect, 16, 101-118.

BROWN, L. M. \& TOWER, J. E. C. (1990) Psychiatrists in primary care: would general practitioners welcome them? British Joumal of General Practice, 40, 369-371.

DANIEL, W. W. (1991) Statistical tables. In Blostatistics: a foundation for analysis in the health sciences. Middlesex: John Wiley \& Sons.

DeParTMENT OF HEALTH (1989) The Children Act 1989. An introductory guide for the NHS. HMSO.

DYER, C. (1992) Placing children in adult psychiatric wards. British Medical Journal, S04, 462-463.

INSTTIUTE OF HEALTH SERVICES MANAGEMENT (1993) Fundholding general practices. In The Hospital and Health Services Year Book. London: The Institute of Health Services Management.

MALEK, M. \& CHILDRENS SOCIETY (1991) Psychiatric Admissions: a report on young people entering residential psychiatric care. London: Cedar Press.

Mannarino, A. P. \& CohEN, J. A. (1986) A clinicaldemographic study of sexually abused children. Child Abuse \& Neglect, 10, 17-23.

Nicol, A. R. (1992) An ethnic awareness training day. Psychiatric Bulletin, 16, 301-302.

Pfeiffer, S. I. \& STRZEleck. B. A. (1990) Inpatient psychiatric treatment of children and adolescents; a review of outcome studies. Joumal of American Academy of Child and Adolescent Psychiatry. 29, 847-853.

T. I. R. Mutale, Senior Registrar in Child and Adolescent Psychiatry, Department of Psychological Medicine, Great Ormond Hospital Trust, Great Ormond Street, London WC1 3JH 